\title{
Analisis Kebutuhan Tenaga Kerja Optimal dengan Metode Work Load Analysis (WLA) pada Extruder Technician I di Departemen Produksi
}

\author{
Nur Prangawayu ${ }^{1 *}$, Fitrah Japunk Lucky Anto ${ }^{2}$, Jayanti Yosepha Simangunsong ${ }^{3}$ \\ ${ }^{1,2,3}$ Program Studi Teknik Industri, Universitas Pembangunan Nasional "Veteran" Yogyakarta, Yogyakarta, Indonesia \\ ("nprangawayu@gmail.com)
}

\begin{abstract}
Abstrak - PT XYZ merupakan perusahaan yang menyediakan berbagai jenis pipa air dan sambungan (fitting) beserta lem PVC untuk memenuhi setiap kebutuhan terkait sistem perpipaan. Berdasarkan hasil observasi, diketahui bahwa dalam menjalankan proses produksinya memiliki beban kerja yang belum merata. Hal ini didasari dengan adanya operator yang menganggur saat operator lainnya mengerjakan tugas di jam yang sama. Padahal tanggung jawab Extruder Technician I cukup banyak. Ketidakseimbangan ini membuat operator dengan beban kerja yang berlebih akan menerima beberapa dampak buruk seperti lebih mudah lelah sehingga konsentrasi dapat menurun dan cenderung tidak produktif. Analisis ini dilakukan dengan Metode Work Load Analysis (WLA). Metode ini dapat memberikan penjelasan terkait beban kerja yang diterima oleh suatu unit perusahaan sehingga usulan pengoptimalan beban kerja dapat diberikan. Setelah dilakukan analisis, dihasilkan output berupa rekomendasi kebijakan pengoptimalan beban kerja dengan memberikan insentif berdasarkan beban kerja dan tidak melakukan penambahan jumlah tenaga kerja. Hal ini dikarenakan rekomendasi ini memiliki nilai efisiensi yang lebih baik dibandingkan dengan dilakukannya penambahan tenaga kerja, perusahaan hanya perlu mengeluarkan total biaya insentif sebesar Rp. $\mathbf{5 . 0 3 2 . 5 7 5}$,- untuk tiga orang pekerja dibandingkan harus mengeluarkan biaya Rp. 6.000.000,- untuk satu orang pekerja tambahan.
\end{abstract}

Kata kunci: beban kerja; insentif; ketidakseimbangan; Metode Work Load Analysis; tenaga kerja

\section{PENDAHULUAN}

Perkembangan dunia industri di era digital ini semakin pesat. Persaingan antar perusahaan yang semakin ketat menuntut setiap perusahaan untuk terus melakukan improvement guna bertahan di kompetisi perebutan pasar, salah satunya adalah dengan meningkatkan produktivitas produksi dan meminimalisir persentase defect yang diterima costumer. PT XYZ merupakan perusahaan manufaktur yang memproduksi pipa dan fitting. Perusahaan ini memproduksi pipa secara 24 jam tanpa henti. Hal ini berakibat pada banyaknya pipa yang diproduksi Departemen Produksi dan produk yang harus diinspeksi serta dianalisis oleh karyawan, yang dalam hal ini adalah bagian dari tugas Extruder Technician I. Extruder Technician I pada Departemen Produksi terbagi menjadi empat zona pada yaitu zona I, zona II, zona III, dan zona IV. Lalu dalam menjalankan proses produksinya, khususnya pada zona III memiliki beban kerja yang belum merata. Hal ini didasari dengan adanya operator yang menganggur saat operator lainnya mengerjakan tugas di jam yang sama. Ketidakseimbangan ini membuat operator dengan beban kerja yang berlebih akan menerima beberapa dampak buruk seperti lebih mudah lelah sehingga konsentrasi dapat menurun dan cenderung tidak produktif. Berdasarkan uraian tersebut, pengukuran terhadap beban kerja tiap operator pada zona III masing-masing shift perlu untuk dilakukan sehingga dapat diketahui kebijakan untuk mengoptimalkan beban kerja. Analisis ini dilakukan dengan Metode Work Load Analysis (WLA).

Beberapa peneliti sebelumnya berpendapat bahwa perbaikan beban kerja yang melebihi batas maksimal adalah dengan melakukan penambahan tenaga kerja saja, seperti yang diungkapkan (Budaya \& Muhsin, 2018) dan (Moektiwibowo dkk., 2016). Kemudian juga dilakukan penentuan beban kerja tiap proses dan mempertimbangkan aspek insentif dan tenaga kerja dalam pengoptimalan beban kerja (Prabowo dkk., 2017). Pada penelitian ini, dilakukan penentuan beban kerja pada tiap individu dalam jabatan yang sama serta mempertimbangkan aspek insentif dan tenaga kerja dalam pengoptimalan beban kerja.

Dari uraian tersebut, rumusan masalah penelitian ini adalah bagaimana menentukan rekomendasi pengoptimalan dari beban kerja Extruder Technician I pada zona III yang tepat. Sedangkan tujuannya adalah memberikan usulan rekomendasi kebijakan pengoptimalan beban kerja secara optimal. Adapun manfaat dilakukannya penelitian ini adalah terwujudnya kebijakan terhadap tenaga kerja yang sesuai terhadap beban kerjanya. 


\section{STUDI LITERATUR}

\section{A. Beban Kerja}

Meshkati dalam Tarwaka (2015) menyatakan bahwa beban kerja dapat dikatakan sebagai perbedaan antara kapasitas pekerja dengan job description dari pekerjaan tersebut. Selain itu, beban kerja muncul dari interaksi antara tuntutan pekerjaan, keterampilan, dan persepsi pekerja (Tarwaka, 2011). Oleh karena itu, beban kerja untuk setiap pekerja sudah ditentukan oleh perusahaan dalam bentuk standar kerja. Kebutuhan sumber daya manusia dapat dilakukan dengan mengidentifikasi output yang ingin dicapai. Kebutuhan tersebut kemudian diterjemahkan ke dalam waktu kerja karyawan. Analisis beban kerja berkaitan erat dengan perubahan demand, dimana perubahan tersebut berbanding lurus dengan tingkat produksi yang harus dipenuhi.

\section{B. Work Sampling}

Work sampling adalah salah satu metode untuk menentukan beban kerja, teknik ini dilakukan dengan melakukan banyak pengamatan instan terhadap suatu populasi dalam waktu tertentu (Yanti, 2017). Ramadhan dkk. (2014) menambahkan bahwa metode ini dapat mengukur produktivitas karyawan dengan menghitung waktu produktif dan waktu non produktif dalam satuan jam kerja karyawan. Terdapat tiga fungsi utama work sampling, yaitu (1) Activity and delay sampling, untuk mengukur aktivitas beserta penundaannya dari seorang karyawan. (2) Performance sampling, untuk mengukur waktu produktif dan non-produktif. (3) Work measurement, untuk menetapkan waktu standar dari suatu kegiatan atau tugas.

\section{Rating Factor}

Rating factor adalah suatu ukuran subjektif untuk menormalkan waktu kerja dengan menambahkan keadaan yang dialami oleh karyawan. Hal ini karena waktu kerja antar karyawan tidak sama, seperti seorang karyawan berpengalaman akan dapat menguasai pekerjaan yang ditetapkan dengan baik tanpa upaya berlebihan, sedangkan karyawan baru perlu melakukan upaya tertentu. Rating factor dapat diperoleh dengan beberapa pendekatan, salah satunya dengan Metode Westinghouse. Metode Westinghouse adalah metode untuk menentukan rating factor dengan mempertimbangkan empat faktor yang dianggap mempengaruhi kewajaran atau ketidakwajaran dalam bekerja, yaitu keterampilan, usaha, kondisi kerja, dan konsistensi (Nurhasanah dkk., 2014). Berikut ini merupakan penjelasan mengenai faktor yang berpengaruh dalam Metode Westinghouse.

1. Keterampilan (Skill), merupakan kemampuan karyawan dalam mengikuti tata cara kerja yang telah ditetapkan.

2. Usaha (Effort), merupakan kesungguhan yang ditunjukkan oleh karyawan saat melakukan pekerjaan.

3. Kondisi kerja (Condition), merupakan faktor dimana kondisi lingkungan secara fisik (pencahayaan, kebisingan, dan suhu) dapat berpengaruh terhadap performance karyawan.

4. Konsistensi (Consistency), merupakan faktor yang menjadi tolak ukur apakah hasil kerja dari karyawan terlalu bervariasi atau tidak.

Angka-angka yang diperoleh dari keempat faktor tersebut selanjutnya dianalisis sesuai kelasnya yang dapat dilihat pada Gambar 1. Kemudian data diolah menggunakan persamaan 1 dan persamaan 2 untuk menghasilkan besaran nilai rating factor.

$$
\begin{gathered}
R f=S+E+C+C o \\
P=1-R f
\end{gathered}
$$

Keterangan:

$\mathrm{Rf}:$ Besaran rating factor
$\mathrm{S}:$ Skill
$\mathrm{E}:$ Effort
$\mathrm{C}:$ Condition
$\mathrm{Co}:$ Consistency
$\mathrm{P}:$ Rating factor


Tabel 1

Penyesuaian Westinghouse

\begin{tabular}{ccc|ccc}
\hline \multicolumn{3}{c|}{ SKILL } & \multicolumn{3}{c}{ EFFORT } \\
\hline$+0,15$ & A1 & Superskill & $+0,13$ & A1 & Superskill \\
$+0,13$ & A2 & & $+0,12$ & A2 & \\
$+0,11$ & B1 & Excellent & $+0,10$ & B1 & Excellent \\
$+0,09$ & B2 & & $+0,08$ & B2 & \\
$+0,05$ & C1 & Good & $+0,05$ & C1 & Good \\
$+0,03$ & C2 & & $+0,02$ & C2 & \\
0,00 & D & Average & 0,00 & D & Average \\
$-0,05$ & E1 & Fair & $-0,04$ & E1 & Fair \\
$-0,10$ & E2 & & $-0,08$ & E2 & \\
$-0,16$ & F1 & Poor & $-0,12$ & F1 & Poor \\
$-0,22$ & F2 & & $-0,17$ & F2 & \\
\hline \multicolumn{3}{c|}{ CONDITION } & \multicolumn{3}{c}{ CONSISTENSY } \\
\hline$+0,06$ & A & Ideal & $+0,04$ & A & Ideal \\
$+0,04$ & B & Excellent & $+0,03$ & B & Excellent \\
$+0,02$ & C & Good & $+0,01$ & C & Good \\
0,00 & D & Average & 0,00 & D & Average \\
$-0,03$ & E & Fair & $-0,02$ & E & Fair \\
$-0,07$ & F & Poor & $-0,04$ & F & Poor \\
\hline
\end{tabular}

Sumber: (Sutalaksana dkk., 2006)

D. Allowance

Allowance atau kelonggaran dapat diberikan untuk tiga hal, yaitu untuk kebutuhan personal (personal allowance), untuk melepas rasa lelah (fatigue allowance) dan untuk keterlambatan tak terhindarkan (delay allowance). Ketiga hal tersebut pada kenyataannya dibutuhkan oleh pekerja (Montororing, 2018).

1. Personal allowance, adapun yang termasuk ke dalam allowance ini adalah menghilangkan rasa haus, keperluan buang air kecil, atau bercakap-cakap dengan rekan kerja.

2. Fatigue allowance, allowance ini diberikan kepada karyawan yang sedang kelelahan dan diharuskan melepas rasa lelah dan bekerja pada performansi normal.

3. Delay allowance, allowance ini didasari setiap pekerjaan tidak akan lepas dari hambatan.

Mekanisme penentuan besar allowance dilakukan dengan menentukan besar kelonggaran pada ketiga hal tersebut. Semua itu kemudian dijumlahkan dan diperoleh besar persentase allowance.

\section{E. Metode Work Load Analysis (WLA)}

Metode Work Load Analysis merupakan metode untuk menentukan beban kerja yang dibutuhkan secara deskriptif oleh suatu unit perusahaan. Metode ini dapat menginformasikan alokasi sumber daya manusia secara optimal sesuai dengan beban kerja (Wardah \& Adrian, 2017). Penggunaan metode WLA dapat memenuhi kebutuhan untuk meningkatkan efektivitas, efisiensi, dan profesionalisme dari sumber daya manusia di setiap tugasnya. Metode WLA dapat digunakan dalam berbagai permasalahan, seperti analisis tingkat ergonomi, tingkat keselamatan dan kesehatan kerja, dan sebagainya. Dari penjelasan tersebut, Prabowo dkk. (2017) merumuskan beban kerja sebagaimana pada persamaan 3 .

$$
\mathrm{BK}=\frac{\% \mathrm{P} \times \mathrm{Rf} \times \mathrm{N} \times(1+\% \text { Allowance })}{\mathrm{N}}
$$

Keterangan:

BK : Beban kerja

$\% \mathrm{P}$ : Persentase kegiatan produktif

Rf : Performance rating

$\mathrm{N}$ : Total pengamatan dalam satuan menit 


\section{METODOLOGI}

\section{A. Objek Penelitian}

Objek Penelitian ini adalah Extruder Technician I pada zona III di Departemen Produksi.

\section{B. Metode Pengumpulan Data}

Pengumpulan data dilakukan untuk mengumpulkan informasi yang diperlukan dalam penelitian. Berdasarkan sumbernya, pengumpulan data dibagi menjadi dua, yaitu data primer dan data sekunder. Adapun dalam penelitian ini menggunakan data primer dan data sekunder.

a. Data Primer

Data primer adalah data yang didapatkan secara langsung dari sumbernya (In \& Asyik, 2019). Adapun pengumpulan data primer dalam penelitian ini dilakukan dengan beberapa cara sebagai berikut:

1. Observasi, dilakukan dengan pengamatan dan pencatatan terhadap objek secara sistematis. Diperoleh data berupa data kegiatan produktif dan non-produktif karyawan, performance rating dan allowance.

2. Wawancara, dilakukan dengan memberikan serangkaian pertanyaan kepada pihak terkait, dalam hal ini notaris perusahaan terkait job description dan gaji karyawan.

b. Data Sekunder

Data sekunder meliputi data yang diperoleh dengan melakukan pengumpulan data yang telah ada di perusahaan berupa arsip perusahaan. Data yang dimaksud adalah data struktur organisasi dan jumlah karyawan aktif saat ini.

\section{Kerangka Penelitian}

Kerangka penelitian merupakan langkah-langkah dalam melakukan penelitian. Kerangka penelitian ditulis secara sistematis dan jelas agar tujuan penelitian dapat dicapai. Adapun kerangka penelitian ini dapat dilihat pada Gambar 1. 


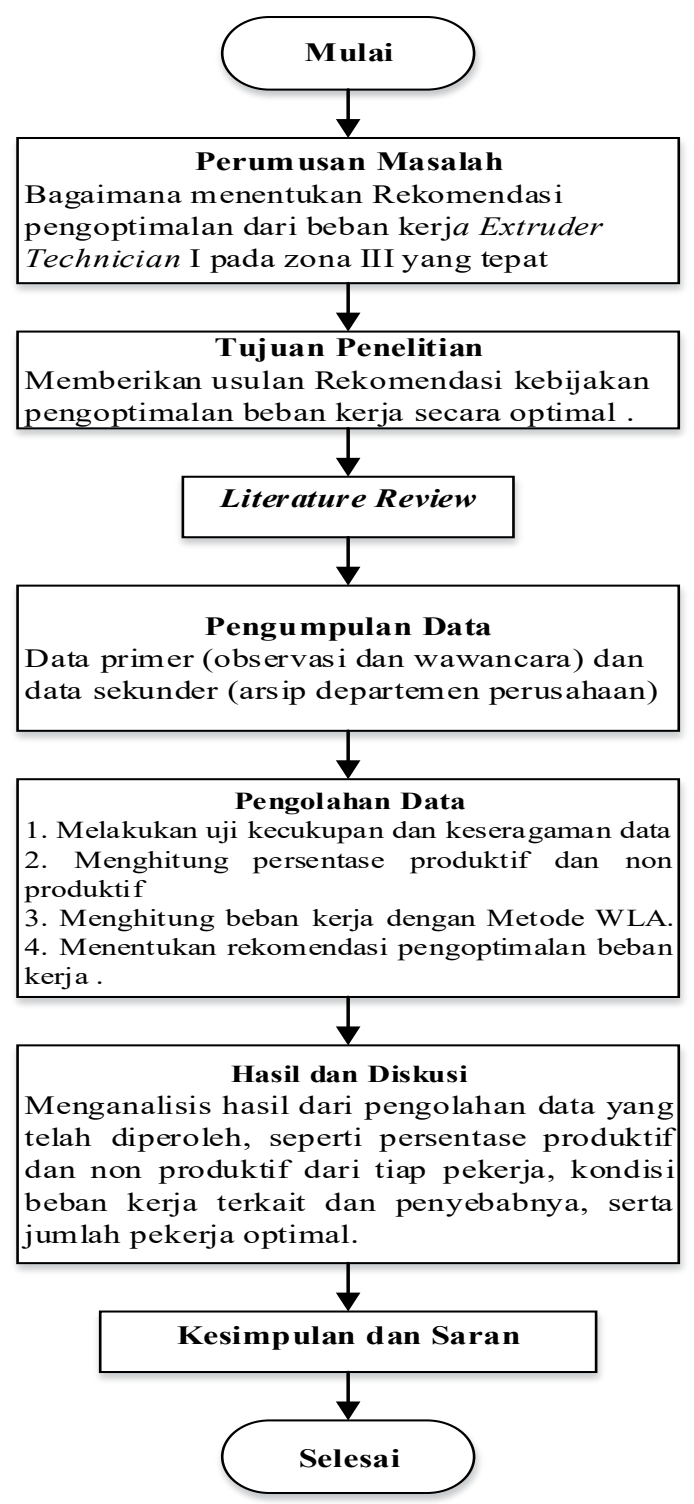

Gambar 1. Flowchart penelitian

\section{HASIL DAN DISKUSI}

\section{A. Hasil}

Job description Extrusion Technician I menjadi dasar dari penentuan aktivitas produktif dan non produktif. Penentuan ini didasarkan pada pembandingan antara job description jenis pekerjaan dengan kegiatan riil saat observasi berlangsung. Data jumlah kegiatan produktif dan non produktif yang diperoleh selama observasi dapat dilihat pada Tabel 2. Lalu, dilakukan penentuan rating factor dengan Metode Westinghouse dan penentuan allowance. Penentuan rating factor ini disesuaikan dengan tiap pekerjanya saat observasi berlangsung, sehingga menghasilkan besaran rating yang berbeda di tiap pekerjanya. Sedangkan penentuan allowance menghasilkan nilai yang sama di tiap pekerjanya karena lingkungan yang dialami sama. Kedua faktor ini ditentukan untuk menghasilkan hasil yang semakin mendekati sistem nyata. Adapun hasil perhitungan rating factor dan allowance dapat dilihat pada Tabel 3. 
Tabel 2

Data jumlah kegiatan produktif dan non produktif

\begin{tabular}{cccc}
\hline \multirow{2}{*}{ Pekerja } & \multirow{2}{*}{ Hari Ke- } & \multicolumn{2}{c}{ Kegiatan } \\
\cline { 2 - 4 } & & Produktif & Non Produktif \\
\hline \multirow{2}{*}{ Pak Syamsul } & 1 & 41 & 29 \\
\cline { 2 - 4 } & 2 & 44 & 26 \\
\hline \multirow{2}{*}{ Pak Sudiro } & 1 & 50 & 20 \\
\cline { 2 - 4 } & 2 & 50 & 20 \\
\hline \multirow{2}{*}{ Pak Dinar } & 1 & 52 & 18 \\
\cline { 2 - 4 } & 2 & 54 & 16 \\
\hline
\end{tabular}

Tabel 3

Hasil perhitungan rating factor dan allowance

\begin{tabular}{ccc}
\hline Pekerja & Rating Factor & Allowance $(\%)$ \\
\hline Pak Syamsul & 1,15 & 57,5 \\
\hline Pak Sudiro & 1,2 & 57,5 \\
\hline Pak Dinar & 1,19 & 57,5 \\
\hline
\end{tabular}

Kemudian dilakukan uji kecukupan data untuk mengetahui apakah data yang diambil telah mewakili kondisi riil atau tidak. Dalam perhitungan ini digunakan tingkat keyakinan sebesar $90 \%$ dan tingkat ketelitian 0,1. Hasil perhitungan uji kecukupan data dapat dilihat pada Tabel 4.

Tabel 4

Hasil perhitungan uji kecukupan data

\begin{tabular}{cccc}
\hline Pekerja & N & N' & Keterangan \\
\hline Pak Syamsul & 140 & 64,937 & N $>N^{\prime}$, maka data cukup \\
\hline Pak Sudiro & 140 & 55,561 & N $>N^{\prime}$, maka data cukup \\
\hline Pak Dinar & 140 & 50,061 & N $>N^{\prime}$, maka data cukup \\
\hline
\end{tabular}

Uji keseragaman data dilakukan untuk mengetahui apakah data yang diperoleh telah seragam atau tidak. Hasil dari uji ini dapat dilihat pada Tabel 5.

Tabel 5

Hasil perhitungan uji keseragaman data

\begin{tabular}{ccccc}
\hline Pekerja & \%Produktif & BKA & BKB & Keterangan \\
\hline Pak Syamsul & 60,714 & 0,690 & 0,525 & Data seragam \\
\hline Pak Sudiro & 71,429 & 0,791 & 0,638 & Data seragam \\
\hline Pak Dinar & 75,714 & 0,830 & 0,685 & Data seragam \\
\hline
\end{tabular}

Kemudian dilakukan penentuan beban kerja dengan Metode Work Load Analysis (WLA). Apabila beban kerja yang diperoleh lebih dari 100\%, maka beban kerja melebihi batas maksimal (Anggara, 2011), sehingga diperlukan penambahan tenaga kerja atau insentif pada pekerja. Hasil perhitungan beban kerja dapat dilihat pada Tabel 6.

Tabel 6

Hasil perhitungan beban kerja

\begin{tabular}{ccc}
\hline Pekerja & \%Beban Kerja & Keterangan \\
\hline Pak Syamsul & 109,97 & Beban kerja melebihi batas maksimal \\
\hline Pak Sudiro & 135,00 & Beban kerja melebihi batas maksimal \\
\hline Pak Dinar & 141,91 & Beban kerja melebihi batas maksimal \\
\hline
\end{tabular}




\section{B. Diskusi}

Terdapat dua rekomendasi dalam pengoptimalan beban kerja pada Extruder Technician I. Pertama dengan melakukan penambahan jumlah pekerja sehingga perusahaan akan mengeluarkan biaya untuk pekerja tambahan. Penentuan pada rekomendasi awal ini mempertimbangkan beban kerja dari tiap pekerja. Adapun penentuan jumlah tenaga kerja optimal dapat ditentukan dengan perhitungan sebagai berikut:

Total beban kerja $\quad=(109,97+135+141,91) \%=386,88 \%$

Rata-rata beban kerja (sekarang) $=\frac{386,88}{3}=128,96 \%$ (belum optimal)

Rata-rata beban kerja (usulan) $\quad=\frac{386,88}{4}=96,72 \%$ (optimal)

Berdasarkan perhitungan tersebut, maka usulan penambahan tenaga kerja yang memiliki persentase beban kerja optimal atau di bawah $100 \%$ untuk ketiga pekerja tersebut adalah satu orang. Hal ini karena dengan empat orang pekerja di departemen yang sama akan membuat persentase rata-rata beban kerja yang diterima menurun sebesar $32,24 \%$, dari yang awalnya $128,96 \%$ menjadi $96,72 \%$. Selain itu, dasar dari penetapan usulan ini dikarenakan ketiga pekerja memiliki job description dan lingkungan kerja yang sama, sehingga penambahan tenaga kerja yang dilakukan sesuai. Penggunaan rekomendasi ini mengharuskan keluarnya gaji untuk satu pekerja tambahan tersebut sebesar Rp. 6.000.000,- per bulan per pekerja. Adapun hasil penentuan tenaga kerja optimal dapat dilihat pada Tabel 7.

Tabel 7

Hasil penentuan tenaga kerja optimal Metode WLA

\begin{tabular}{ccc}
\hline Pekerja & \%Beban Kerja & Usulan Tenaga Kerja Optimal \\
\hline Pak Syamsul & 109,97 & \\
\cline { 1 - 2 } Pak Sudiro & 135,00 & 1 Pekerja \\
\hline Pak Dinar & 141,91 & \\
\hline
\end{tabular}

Sedangkan pada rekomendasi kedua adalah dengan melakukan pemberian insentif dengan didasari pada beban kerja dan tidak melakukan penambahan tenaga kerja. Pada rekomendasi ini, pemberian insentif pada tiap pekerja dikatakan sebagai bentuk kompensasi dari beban kerja yang tinggi. Jumlah insentif yang diberikan kepada tiap pekerja diperoleh dari hasil kali antara kelebihan beban kerja per pekerja dengan gaji pekerja per bulannya yang sebesar Rp. 6.000.000,-. Hasil perhitungan dapat dilihat pada Tabel 8. Berdasarkan Tabel 8, maka pemberian insentif untuk ketiga pekerja yang memiliki beban kerja tinggi adalah sebesar Rp. 5.032.575,-

Tabel 8

Hasil penentuan insentif Metode WLA

\begin{tabular}{|c|c|c|c|}
\hline Pekerja & \%Beban Kerja & Kelebihan Beban Kerja & Insentif \\
\hline Pak Syamsul & 109,97 & $8,97 \%$ & Rp. 538.125 \\
\hline Pak Sudiro & 135,00 & $34 \%$ & Rp. 2.040 .000 \\
\hline Pak Dinar & 141,91 & $40,91 \%$ & Rp. 2.454 .450 \\
\hline \multicolumn{3}{|c|}{ Total } & Rp. 5.032.575 \\
\hline
\end{tabular}

Dari kedua rekomendasi yang diberikan terkait dengan penambahan atau tidak dari jumlah tenaga kerja dan insentif, maka rekomendasi yang dipilih adalah rekomendasi kedua yaitu memberikan insentif berdasarkan beban kerja dan tidak melakukan penambahan jumlah tenaga kerja. Rekomendasi ini dinilai memiliki nilai efisiensi yang lebih baik dibandingkan dengan dilakukannya penambahan tenaga kerja, khususnya dari segi biaya, hal ini karena perusahaan hanya perlu mengeluarkan total biaya insentif sebesar Rp. 5.032.575,- untuk tiga orang pekerja dibandingkan harus mengeluarkan biaya Rp.6.000.000,- untuk satu orang pekerja tambahan. 


\section{KESIMPULAN}

Kesimpulan dari penelitian ini adalah beban kerja yang diterima pekerja pada Extruder Technician I Departemen Produksi Pipa PVC masih melebihi batas beban maksimal. Sehingga dilakukan beberapa rekomendasi pengoptimalan beban kerja, yang menghasilkan rekomendasi terpilih yaitu melakukan pemberian insentif berdasarkan beban kerja dan tidak melakukan penambahan jumlah tenaga kerja. Rekomendasi ini dinilai memiliki nilai efisiensi yang lebih baik dibandingkan dengan dilakukannya penambahan tenaga kerja dari segi biaya, hal ini karena perusahaan hanya perlu mengeluarkan total biaya insentif sebesar Rp. 5.032.575,- untuk tiga orang pekerja dibandingkan harus mengeluarkan biaya Rp. 6.000.000,- untuk satu orang pekerja tambahan.

Penelitian ini dapat mengusulkan kepada manajemen dalam hal pengambilan keputusan penentuan beban kerja optimal pada tenaga kerja sehingga menghasilkan lingkungan profesional yang sehat dan berakibat pada peningkatan profit perusahaan. Sedangkan untuk implikasi pada dunia akademik adalah sebagai bentuk pengembangan dari penelitian Metode WLA terdahulu yaitu dengan hadirnya dua jenis rekomendasi dengan mempertimbangkan jumlah tenaga kerja dan insentif yang diberikan sehingga menghasilkan keputusan yang lebih baik. Pada penelitian ini, nilai kebaruan yang didapat adalah dilakukannya penentuan beban kerja pada tiap individu dalam jabatan yang sama serta mempertimbangkan aspek insentif dan tenaga kerja dalam pengoptimalan beban kerja. Adapun pada penelitian selanjutnya dapat mempertimbangkan parameter lain dalam penentuan pengambilan keputusan selain dari aspek ekonomi.

\section{DAFTAR PUSTAKA}

Anggara, R. (2011). Pengukuran Produktivitas Berdasarkan Beban Kerja (Studi Kasus Pada Industri Kerupuk). Jakarta: Universitas Gunadarma

Budaya, P., \& Muhsin, A. (2018). Workload Analysis In Quality Control Department. Jurnal Optimasi Sistem Industri, 134-140.

In, A., \& Asyik, N. (2019). Pengaruh kompetensi dan independensi terhadap kualitas audit dengan etika auditor sebagai variabel pemoderasi. Jurnal Ilmu dan Riset Akuntansi (JIRA), 1-15.

Moektiwibowo, H., Rahmawati, A., \& Arianto, B. (2016). Optimalisasi Beban Kerja Operator Menggunakan Metode Work Load Analysis (WLA) Pada Operator Filling Liquid. Jurnal Teknologi Industri, 62-73.

Montororing, Y. D. (2018). Usulan Penentuan Waktu Baku Proses Racking Produk Amplimesh dengan Metode Jam Henti pada Departemen Powder Coating. Jurnal Teknik: Universitas Muhammadiyah Tangerang, Vol. 7, No. 2, 53-63.

Nurhasanah, N., Haidar, F. Z., Hidayat, S., Hasanati, N., Listianingsih, A., \& Agustini, D. (2014). Penjadwalan Produksi Industri Garmen dengan Simulasi Flexsim. Jurnal Ilmiah Teknik Industri, Vol. 2 No. 3, 141148.

Prabowo, A., Setiawan, H., \& Umiyati, A. (2017). Analisa Beban Kerja Dan Penentuan Tenaga Kerja Optimal Dengan Pendekatan Work Load Analysis (WLA). Jurnal Teknik Industri Vol. 5 No. 1, 40-45.

Ramadhan, R., Tama, I. P., \& Yanuar, R. (2014). Analisa Beban Kerja dengan Menggunakan Work Sampling dan Nasa TLX untuk Menentukan Jumlah Operator (Studi Kasus: PT XYZ). Jurnal Rekayasa dan Manajemen Sistem Industri, 926-973

Sutalaksana, I., Anggawisastra, R., \& Tjakraatmadja, J. (2006). Teknik Perancangan Sistem Kerja. Bandung: Jurusan Tekknik Industri, Institut Teknologi Bandung.

Tarwaka. (2011). Keselamatan dan Kesehatan Kerja. Surakarta: Harapan Press.

Tarwaka, B., \& Sudiadjeng. (2015). Ergonomi Untuk Kesehatan, Keselamatan Kerja dan Produktivitas. Jakarta: Penerbit UNIBA Press.

Wardah, S., \& Adrian, N. (2017). Penentuan Jumlah Karyawan yang Optimal pada Penanaman Lahan Kelapa Sawit dengan Menggunakan Metode Work Load Analysis (WLA) (Studi Kasus: PT. Bumi Palma Kabupaten Indragiri Hilir Riau). Jurnal Sains, Teknologi dan Industri, Vol. 15, No. 1, 28-34.

Yanti, G. (2017). Produktivitas Tenaga Kerja dengan Metode Work Sampling Proyek Perumahan di Kota Pekanbaru. Jurnal Teknik Sipil Siklus, Vol. 3, No. 2, 100-106. 